\title{
INTERSECTING IDENTITIES AND THE WORK OF FACULTY DEVELOPMENT
}

\author{
Cerri A. Banks, Jonathan Iuzzini, Susan M. Pliner, \\ Hobart and William Smith Colleges
}

On increasingly diverse college campuses, faculty members look to faculty developers for support in facilitating difficult classroom dialogues and in handling challenging interactions around their students' identities and their own. We propose that faculty developers' work around issues of diversity, social justice, and inclusive excellence can be enhanced by developing a foundation in the theory of intersectionality, which engages the complexity of identity and the resulting power structures that inform institutions. We discuss this theoretical perspective and provide examples of faculty development initiatives that can be strengthened through the use of an intersectional lens.

What does it feel like to be a faculty member preparing to teach on a Monday or Tuesday, just as a racist incident that occurred on campus over the weekend has begun to gain attention? Suppose a noose was found hanging from a tree on campus, as was the case at the University of Maryland, California State University at Fullerton, Purdue University, and Columbia University in recent years (Jones, 2007). Perhaps a predominantly white fraternity hosted a party at which students dressed in blackface, or as slaves, or entered the party by crawling under a barbedwire fence as part of a "crossing the border" theme (Jones, 2007).

Students are likely to arrive at class with a range of emotions about what they have heard or experienced. For students of any background who are passionate about the struggle for social justice, such incidents are deeply troubling and may evoke feelings of disappointment, fear, or anger. For students who have had less interaction with people different from themselves or whose attitudes lead them to minimize the power of such incidents, the reaction of their peers may seem to be blowing the event 
out of proportion, an overreaction. One explanation for the divergence in how such events are processed is that the acts themselves are not always intended to be offensive. Because the actors in these incidents may be focused on the ways in which their acts are humorous and ironic to themselves as a group, they may fail to think through the ways in which others could perceive their acts as hurtful, insensitive, offensive, and threatening. Students from across this spectrum will be looking for guidance from faculty about how to process these events, but many faculty members feel unprepared to discuss them.

In faculty development workshops, new faculty orientations, campus forums, and classroom observations, we have heard educators articulate their concerns about dealing with difficult conversations in their classrooms in a number of ways. These include feeling unprepared to answer unexpected questions, feeling disconnected from issues related to identity, feeling culturally different from students, and feeling worried that attention to these matters will result in less content being covered. In addition, at institutions that lack support for matters related to diversity, inclusive excellence, and social justice, faculty can feel isolated in their classrooms and apprehensive about reaching out to departmental colleagues for support. A successful faculty developer must be prepared to support professors in the work of acknowledging, facilitating, and at times confronting controversial topics in the classroom.

Historically, academic literature and faculty development practice has focused on classrooms, where the course content lends itself easily to discussions about difficult topics and faculty have chosen to engage with students in this way (Duncan-Andrade, 2008; Fox, 2001; Newman, 2007). For example, in a course on race, class, and gender, both students and faculty expect controversial conversations, heated debate, challenging questions, and collaborative inquiry related to identity and power. This is not always the case in a chemistry class. Yet controversy may arise not only from verbal interactions or course themes. Classroom practices-for example, group work, who gets called on in class and is therefore seen as knowledgeable, and decisions about class content-are always connected to who is in the classroom at any given time. Student and faculty relationships are always in flux based on the interactions that occur, making it inevitable that classroom challenges connected to identity will arise.

\section{The Theory of Intersectionality}

Dill and Zambrana (2009) described intersectionality as "an innovative and emerging field of study that provides a critical analytic lens to interrogate racial, ethnic, ability, age, sexuality, and gender disparities and to contest 
existing ways of looking at these structures of inequality, transforming knowledges as well as the social institutions in which they have found themselves" (p. 1). In other words, intersectionality examines identity and its relationship to power. It moves beyond individual examinations of difference and highlights institutional structures and the ways in which unequal power relationships are recreated and reinforced in everyday language, media, legal systems, and higher education (Banks, 2009; Howard, 1999). Intersectionality incorporates systemic reasons for inequality with a goal of institutional change.

Feminist scholars have outlined specific features that explain the usefulness of intersectionality (Brewer, 1999; Collins, 1998, 2000; Crenshaw, 1993; Dill \& Zambrana, 2009). The following specific components of the theory relate directly to the work of faculty developers:

- Race, class, gender, sexuality, and other markers of identity are "simultaneous and overlapping spheres of oppression" that are important to daily life on both individual and systemic levels (Collins, 2000, p. 22). Thus, all of the features of identity that an individual holds are at play in every experience. For example, intersectionality recognizes that biological features (skin color) have social consequences (race). Individuals may share identities, but there are differences both among and between groups. In their work, faculty developers must recognize that societal norms like stereotypes are connected to identity and played out in college classrooms. They must acknowledge the social consequences of both privilege and oppression that faculty and students may face concurrently as a result of their multiple, intersecting identities (Kendall, 2006; Rothenberg, 2008). Understanding these points requires making opportunities for dialogue and reflection.

- Intersectionality employs "both/and rather than either/or categorizations" of identity and experience (Brewer, 1999, p. 33). Either-or categorizations force individuals to rank the significance of features of identity in any given experience. Both-and categorization is inclusive and recognizes that all aspects are significant. For example, a black woman and a white woman will both experience sexism. Yet the black woman cannot separate her struggle against racism from her struggle against sexism, while the white woman can make choices unburdened by her racial identity. Along these lines, it is important for faculty developers to recognize the multiple complexities to consider when consulting with faculty members on issues related to identity in the classroom. Faculty developers should understand that both-and categorization makes space for all features of identity to be included in conversations. This can help faculty 
understand the complexities of student lives and lead inclusive and expansive classroom discussions.

- Intersectionality "challenges traditional modes of knowledge production in the United States and provides an alternative model that combines advocacy, analysis, theorizing, and pedagogy" (Dill \& Zambrana, 2009, p. 1). Such a multifaceted approach to pedagogy incorporates the idea that educational practices should move beyond traditional ways of teaching and learning. It posits that valuable knowledge originates from individuals and groups whose voices are often marginalized. Including these voices can create new dialogues and new outcomes. For example, faculty developers can help faculty understand that all students bring important knowledge into a classroom setting. This knowledge comes from many places and is not always connected to traditional understandings. Faculty must find ways to show that they value all student voices in order to facilitate equity in the classroom. Faculty developers must also understand, and be prepared to address in training and consultations, that because of both visible and presumed identity markers, faculty may be challenged by students regarding the validity of their authority and knowledge on a given topic or discipline.

- Intersectionality "reconstructs lived experiences, historical positioning, cultural perceptions, and social constructions" (Brewer, 1999, p. 33). It thus challenges assumed knowledge about the lives of others. For example, much of the knowledge about marginalized groups is steeped in stereotypes. Intersectionality challenges stereotypes by examining history, culture, and society, thereby providing a more expansive analysis that looks at social, political, and economic structures. Since institutional change requires sharing knowledge and power, such analysis fosters a broader way of seeing and understanding others and solving problems. Faculty developers can help faculty members recognize that an intersectional approach supplies them with a wider knowledge base and group of strategies to draw on when they face challenging issues in the classroom.

Faculty developers using an intersectional analysis will help alter the ways educators think about content, policy, and practice. Intersectionality teaches us that no students or faculty, in spite of shared identities, have the same lives or experiences; that systemic inequities and the resulting social, political, and economic power relationships inform our classrooms in complex and dynamic ways; and that the choices we make about managing controversial topics are as important to students' success as course content. In the next section, we show the connection among these four 
features of the theory of intersectionality and the practical work of faculty developers.

\section{Intersectionality and Faculty Development: Connecting Theory to Practice}

When considering specific practices that faculty developers can employ to help educators prepare to handle difficult discussions or interactions in the classroom, we build on the ideas put forth by Salazar, Norton, and Tuitt (2010), who stated, "Faculty developers are vital to interrupting the cycle of inequity. They can be catalysts for faculty to weave inclusive excellence into their practices" (p. 220). Many faculty are anxious or fearful about confronting hot topics and difficult interactions in their classrooms because they feel ill equipped to do so. They may also believe that the potential impact they could have as an individual would be limited.

Faculty developers can lead faculty members to a greater sense of competence and efficacy. One of the lessons we learn from an intersectional analysis is that the embodiment of a particular identity and the understanding of the systemic impact of that embodiment on oneself and others are two different conversations that stem from two different knowledge bases. The first relies on lived experience, and the second draws from learned theoretical understandings. Faculty developers cannot make assumptions about the values that a professor or student may hold and the reasons they do so. They must be prepared to help all faculty members across the range of identities gain the necessary academic knowledge, skills, and strategies to handle hot topics in the classroom. Faculty developers and faculty members must engage in an ongoing process of teaching and learning, with theory informing practice.

\section{Scenarios}

Here we present four scenarios generated by faculty and faculty developers. These examples come from workshops we have facilitated on difficult dialogues and classroom challenges and from classroom observations. For each example, we discuss how a faculty developer's approach to addressing the issue is broadened through an intersectional perspective.

\section{SCENARIO 1}

A faculty member in history reported that during a discussion of a radical film about race, the one black student in the class appeared to be the most reluctant of the students to discuss the issues in the film. One of the white 
students challenged him, essentially calling him racist, and the whole class became deeply uneasy and unsure how to proceed.

Intersectional analysis recognizes that structural inequality has individual consequences. Using this concept can help faculty developers support individual faculty members who are working to make structural changes that will have an impact on student learning. An intersectional analysis would help the professor in this situation recognize that the one black student who was uncomfortable speaking in class should not be expected to carry a special responsibility to do so simply because the discussion focuses on race. For this student, who carries the biological marker of race, a social consequence is the expectation that he should have an advanced understanding of race and that it is his responsibility to teach others who do not have that marker. An additional consequence is that if he does speak about race often, he runs the risk of being pigeonholed by the professor and students as the authority on race rather than as a student who is also there to learn about race. Other students in the classroom may believe that explaining race can be his only worthwhile contribution.

An intersectional analysis allows a faculty developer to help the faculty member challenge the typical inequitable dynamic in which white students sit silently through discussions about race. For example, the faculty developer could provide the faculty member with strategies like the use of a free-write, which would require all students to write a response to the question or incident that arose and then share that response in pairs, a small group, or the class as a whole. In addition, since many white students are reluctant to participate in conversations about race because they believe their lives are not connected to this issue, a professor can be encouraged to include a short assignment (for example, an interview with family members about their history, an autobiography in which they discuss their first experience with difference) to help students recognize that they all have knowledge to share about this topic. Thus, the faculty developer helps the faculty member hold all students accountable to participate fully in classroom discussions as they examine the power relationships at play.

\section{SCENARIO 2}

During a conversation about reproductive rights, a white student said, by way of arguing for the legal right to abortion, "Imagine how many Puerto Ricans there would be in Rochester if abortion was illegal." This student is relying on stereotypes about people of Puerto Rican descent to advocate for maintaining the legality of abortion. Interestingly, the student is making use of a racist ideology to support a "liberal" attitude toward this particular public policy that is most often represented as a matter of gender. 
In this instance, we suggest an approach informed by the second and third tenets of intersectionality. A faculty developer could point out how stereotypical assumptions about multiple social identities (that is, social class, ethnicity, and women's reproductive rights) are at play and intertwined in this student's statement. He or she can remind the faculty member about the ways in which identities and inequalities are socially constructed and about how to interrupt the stereotypical assumptions at play. Employing both-and categorization allows a professor to combine advocacy and pedagogy by asking, "What does this discussion mean for a woman who is Puerto Rican?" and then facilitating a conversation that can create new knowledge. Brookfield and Preskill (2005) and Fox (2001) provide excellent ideas for facilitating civil conversations and classroom confrontations, including setting guidelines, making certain there are opportunities for all voices to be heard, using a range of different models for discussion, and helping faculty members make connections to their specific disciplines.

\section{SCENARIO 3}

In a midsemester evaluation of an introductory economics course, it became clear to the faculty developer that a group of male students who challenged the credibility, preparation, and credentials of the professor, a young white woman, did so based on sexist expectations.

This situation illustrates the third tenet of intersectionality. In traditionally male-dominated disciplines, it is not uncommon for female professors to face skepticism from young males who are used to knowledge in that discipline coming from men. Thus, the professor feels obligated to work harder to prove herself competent since the students' sexist expectations are likely to serve as a filter through which they evaluate her performance. In some cases, it may not occur to the professor that the source of the hostility is gender bias, and the faculty developer may have to point this out. The faculty developer could encourage her to expand her pedagogy, model for students how to challenge traditional ideas about how knowledge is made in that discipline, and provide a broader context for knowledge construction. For example, the faculty developer could suggest that the faculty member assign a reading that deals with sexism in the discipline, construct classroom activities where men and women discuss their experience with the discipline, and invite professionals who engage identity and economics to speak in class.

\section{CHALLENGING ASSUMED KNOWLEDGE}

In each of the scenarios, the fourth described feature of intersectionality is evident. Using intersectionality to reconstruct lived experiences and cultural perceptions will help a professor understand that students 
arrive in the college classroom from a variety of backgrounds and with deeply ingrained cultural values and beliefs. An intersectional understanding motivates the professor to be open to discussing a range of ideas, recognizing both the privilege and oppression from which a student may be speaking and their consequences. The reconstruction of historical positioning and social constructions also gives faculty developers and faculty a wider range of strategies on which to draw in the classroom.

\section{Programming for Intersectionality}

Cook and Sorcinelli (2005) suggest that faculty developers can convey this information at an institutional level through a range of programming methods. We present here examples of specific programmatic initiatives that faculty developers can use to integrate this theory into their practice, taking into consideration the culture of their individual institutions.

\section{TEACHING CONSULTATIONS}

Much has been written about specific methods of individual instructional consultation in developing classroom practice (Brinko \& Menges, 1997; Lewis \& Lunde, 2001; Stanley \& Ford, 2001). Given that consultations can be significant in helping faculty members enrich their pedagogy, we urge faculty developers to view them as an opportune time and safe environment in which to introduce an intersectional perspective. Developing ongoing relationships with faculty, observing classroom interaction, and discussing teaching philosophies are key elements of teaching consultations. With feedback loops, faculty developers can identify problem areas and then work through them with faculty.

In our experience, faculty can make significant gains in inclusive teaching when faculty developers are prepared to conduct individual consultations, observations, and feedback using an intersectional approach. For example, faculty developers can observe and record gender dynamics in the classroom; pay attention to who speaks and who gets called on, and with what frequency, during class discussion; note how faculty members use language and the extent to which that language is inclusive; and look for ways that students use their identity-based privilege to manipulate classroom interactions.

\section{FACULTY READING GROUPS}

In one common practice of faculty developers, the faculty reading group, faculty typically read a common text and engage in discussion and analysis of that text with one another and the faculty developer in several meetings 
over a semester. Reading groups can serve as a catalyst for engaging faculty developers and faculty in construction of foundational knowledge about the principles of intersectionality, diversity, and the complexity of identity. Faculty developers can also guide faculty members immersed in an analysis of selective texts, such as bell hooks's teaching trilogy-Teaching to Transgress (1994), Teaching Community (2003), and Teaching Critical Thinking (2010)-or Paulo Freire's Pedagogy of the Oppressed (2007), to move beyond critical analysis to practical applications for teaching. In addition, the reading group format can illuminate for faculty developers and faculty their own intersecting identities and the subsequent impact those identities have on pedagogy, classroom dynamics, and in the work of faculty development.

Without the foundation of the intersectional approach, these reading groups would likely involve the faculty developer's leading faculty members in a discussion that relies almost exclusively on their personal experiences and disciplinary backgrounds. Certainly there is value in a discussion that stems from these sources of information, but we suggest that discussion of the same text can be deepened by asking critical questions that go beyond individual experiences to an analysis of systemic influences on beliefs and behavior. For example, in the third book in her teaching trilogy, hooks (2010) discusses the often isolating experience of being an African American woman in the predominantly white academy. In a related vein, she presents her framework for engaged pedagogy: "Because engaged pedagogy highlights the importance of independent thinking and each student finding his or her unique voice, this recognition is usually empowering for students. This is especially important for students who otherwise may not have felt that they were 'worthy,' that they had anything of value to contribute" (p. 21).

In a recent discussion of this book, a white woman faculty member commented that it was impossible for her to relate to hooks's experience as an African American and that this disconnect prevented her from understanding the utility of hooks's framework for engaged pedagogy. This faculty member's focus on the racial difference between her and hooks created an obstacle to being able to consider the identities they shared: both are women, and both are academics.

Using an intersectional approach, the faculty developer (also a white woman) facilitated the faculty member's understanding of embodying multiple identities and the impact of these on classroom dynamics. The developer began by modeling how she thought about hooks's framework: that being a woman and an academic enables her to understand certain 
important aspects of the text. Hearing hooks address race reminds her of the need to think about the ways identities intersect and make certain that this insight informs her practice. Including all aspects of identity (both-and categorization) helps her to find points of connection. After sharing her perspective with the group, the faculty developer then posed these questions: Have you had an experience, perhaps in a classroom or at a conference, where you felt disenfranchised in some way, where your voice was not being heard? How might we (perhaps unconsciously) be replicating this dynamic in our classrooms?

We maintain that a faculty developer whose work is informed by intersectionality is better equipped to pose these kinds of critical questions and facilitate faculty members' exploration of material that can enrich their teaching. We have found that the most successful conversations emerge from cross-disciplinary groups where ideas are shared, critiqued, and tested in a supportive, low-stakes environment.

\section{Workshops}

Faculty developers have long used workshops as opportunities to support the professional development of faculty members and socialize them to the campus culture and academic expectations. Workshops can also be used to create a visible institutional expectation for developing one's own understanding of diversity, as well as creating inclusive classrooms. These workshops should include discussions and resources that enable faculty to explore their own intersecting identities and what they mean for classroom practice (Ouellett, 2005).

Developing a workshop on dealing with difficult conversations is a useful tool. Asking faculty members to reflect on their own experiences as students or teachers and to describe scenarios they may have heard from colleagues provides a fertile source of material to establish foundational expectations and a springboard for further faculty development initiatives. Faculty developers can help faculty members brainstorm, critique, and examine a range of responses to these scenarios. For example, having faculty members participate in role plays can help them develop language and model behaviors that facilitate conversation about difficult topics. By working in groups led by the faculty developer, faculty members access the many ways in which complicated issues arise across disciplines and a multitude of perspectives about how to respond. Faculty can learn from the struggles of their colleagues and be encouraged by their success as they discuss what worked well, what did not, and why. 
Developing relationships through these activities provides a support network that lasts well beyond the workshop and can be useful when these issues arise in the classroom or on campus. These workshops should take place on a regular basis at a time when faculty of all career stages can participate, so they can keep current on evolving pedagogical theory and practice related to identity and difference.

\section{Conclusion}

Intersectional analysis transforms knowledge in ways that challenge structures of inequality in institutions like higher education. The classroom is a space where interactions and relationships are as significant to student learning as course content is, although they are not always recognized as such. Intersectional analysis fosters different ways of knowing, pushes the boundaries of traditional pedagogical approaches to include radical critical thinking and analysis skills, and can lead to teaching that supports academic excellence and prepares students for life after college (Banks, 2009; Franklin, 2002).

The concept of intersectionality creates space for all features of identity to be included for critique, application, and analysis in practices associated with teaching and learning. It points to the systemic nature of identity markers and their connection to privilege, power, and dominance. Intersectionality examines how systemic relationships connected to identity reinforce inequitable power relationships that influence both institutions, like higher education, and individual lived experiences. These relationships are often the foundation for challenging classroom dynamics.

Handling hot topics and challenging interactions connected to identity, like the ones described at the start of this chapter, require knowledge and preparation. Faculty developers must learn the relevant theoretical concepts and then make the practical application of that theory visible. To that end, faculty developers must understand their own identities as intersectional and use this understanding to inform their work. They must teach faculty to engage in the same analysis. Faculty developers must be open to learning about and understanding the complexity of the lived experiences of others and how these inform teaching and learning. They cannot assume that identity markers alone make one qualified or not to engage intellectually with issues of difference. By using the concept of intersectionality, faculty developers can help educators across identity backgrounds and academic disciplines create and maintain classrooms that challenge inequitable power relations and are committed to inclusive excellence and student learning. 


\section{REFERENCES}

Banks, C. A. (2009). Black women undergraduates, cultural capital, and college success. New York: Peter Lang.

Brewer, R. M. (1999). Theorizing race, class, and gender: The new scholarship of black feminist intellectuals and black women's labor. Race, Class, and Gender, 6(2), 29-47.

Brinko, K. T., \& Menges, R. J. (Eds.). (1997). Practically speaking: A sourcebook for instructional consultants in bigher education. Stillwater, OK: New Forums Press.

Brookfield, S. D., \& Preskill, S. (2005). Discussion as a way of teaching: Tools and techniques for democratic classrooms (2nd ed.). San Francisco: Jossey-Bass.

Collins, P. H. (1998). Fighting words: Black women and the search for justice. Minneapolis: University of Minnesota Press.

Collins, P. H. (2000). Black feminist thought: Knowledge, consciousness, and the politics of empowerment. New York: Routledge.

Cook, C. E., \& Sorcinelli, M. D. (2005). Building multiculturalism into teaching development programs. In M. Ouellett (Ed.), Teaching inclusively: Resources for course, department, and institutional change in higher education (pp. 74-83). Stillwater, OK: New Forums Press.

Crenshaw, K. (1993). Mapping the margins: Intersectionality, identity politics, and violence against women. Stanford Law Review, 43, 1241-1299.

Dill, B. T., \& Zambrana, R. E. (2009). Critical thinking about inequality: An emerging lens. In B. T. Dill \& R. E. Zambrana (Eds.), Emerging intersections: Race, class, and gender in theory, policy, and practice (pp. 1-21). New Brunswick, NJ: Rutgers University Press.

Duncan-Andrade, J. (2008). Teaching critical analysis of racial oppression. In M. Pollock (Ed.), Everyday antiracism: Getting real about race in school (pp. 156-160). New York: New Press.

Fox, H. (2001). When race breaks out: Conversations about racism in college classrooms. New York: Peter Lang.

Franklin, V. P. (2002). Introduction: Cultural capital and African American education. Journal of African American History, 87(2), 175-180.

Freire, P. (2007). Pedagogy of the oppressed. New York: Continuum.

hooks, b. (1994). Teaching to transgress: Education as the practice of freedom. New York: Routledge.

hooks, b. (2003). Teaching community: A pedagogy of hope. New York: Routledge.

hooks, b. (2010). Teaching critical thinking: Practical wisdom. New York: Routledge. 
Howard, G. R. (1999). We can't teach what we don't know: White teachers, multiracial schools. New York: Teachers College Press.

Jones, V. E. (2007, December 5). "They're sitting right next to us": On college campuses, students continue to struggle with ethnic tensions and racist attitudes. Boston Globe. Retrieved from www.boston.com /lifestyle/articles/2007/12/05/theyre_sitting_right_next_to_us/

Kendall, F. E. (2006). Understanding white privilege: Creating pathways to authentic relationships across race. New York: Routledge.

Lewis, K. G., \& Lunde, J.T.P. (Eds.). (2001). Face to face: A sourcebook of individual consultation techniques for faculty/instructional developers. Stillwater, OK: New Forums Press.

Newman, D. M. (2007). Identities and inequalities: Exploring the intersections of race, class, gender, and sexuality. New York: McGraw-Hill.

Ouellett, M. (Ed.). (2005). Teaching inclusively: Resources for course, department and institutional change in higher education. Stillwater, OK: New Forums Press.

Rothenberg, P. S. (Ed.). (2008). White privilege: Essential readings on the other side of racism (3rd ed.). New York: Worth.

Salazar, M. D., Norton, A. S., \& Tuitt, F. A. (2010). Weaving promising practices for inclusive excellence into the higher education classroom. In L. B. Nilson \& J. E. Miller (Eds.), To improve the academy, Vol. 28. Resources for faculty, instructional, and organizational development (pp. 208-226). San Francisco: Jossey-Bass.

Stanley, C. A., \& Ford, T. F. (2001). Using climate assessment data to consult about multicultural teaching. In K. G. Lewis \& J.T.P. Lunde (Eds.), Face to face: A sourcebook of individual consultation techniques for faculty/ instructional developers (pp. 275-296). Stillwater, OK: New Forums Press. 